\title{
A cross-sectional study of sleep disturbances in patients diagnosed with Functional Dyspepsia
}

\author{
Sejal Grover ${ }^{1}$, Shamshersingh G. Chauhan ${ }^{2}$, Sagar Karia ${ }^{3}$, Nilesh Shah ${ }^{4}$, Avinash De Sousa ${ }^{5}$ \\ ${ }^{1}$ Medical Student, Lokmanya Tilak Municipal Medical College, Mumbai. \\ ${ }^{2}$ Assistant Professor, Department of Gastroenterology, Lokmanya Tilak Municipal Medical College, \\ Mumbai. \\ ${ }^{3}$ Assistant Professor, \\ ${ }^{4}$ Professor and Head, \\ ${ }^{5}$ Research Associate and Consultant Psychiatrist, \\ 3,4,5 Department of Psychiatry, Lokmanya Tilak Municipal Medical College, Mumbai \\ Corresponding Author: Sagar Karia \\ Email: kariabhai117@gmail.com
}

\begin{abstract}
Background: Psychiatric comorbidity in the form of depression and anxiety is very common in patients with gastrointestinal disorders. Patients with functional dyspepsia also have a number of psychological factors that alleviate and exacerbate their condition. The following study was aimed at studying the various forms of sleep disturbances in patients with functional dyspepsia.

Methodology: The study was cross sectional and followed a case-control design. 100 patients with functional dyspepsia attending the gastroenterology outpatient department formed the sample for the study while 100 disease free relatives of these patients were the control group. They were administered the Bowel Symptoms Questionnaire, Pittsburgh Sleep Quality Index and Insomnia Severity Index. The two groups were compared and the data was statistically analysed and presented.

Results: Majority of the subjects in the study were in the age group 30-40 years and were married, employed and educated. Sleep disturbances and poor sleep quality was more in the patient group while they also had significantly greater insomnia of moderate to severe nature compared to controls. Increased severity, frequency and chronicity of the functional dyspepsia correlated with poor sleep quality.

Conclusion: Sleep disturbances are common in patients with functional dyspepsia and need attention and clinical treatment to improve the outcomes of these patients.
\end{abstract}

Key Words: functional dyspepsia, insomnia, sleep, sleep quality.

(Paper received $-30^{\text {th }}$ September 2019, Peer review completed $-18^{\text {th }}$ November 2019 )

(Accepted $-7^{\text {th }}$ December 2019)

\section{INTRODUCTION}

Functional gastrointestinal (GI) disorders include symptoms arising in the mid or lower gastrointestinal tract that cannot be attributed to any anatomic or biochemical defects [1]. Functional dyspepsia (FD) is a very common disorder and of great clinical significance. It is characterized by chronic or recurrent symptoms of upper abdominal pain or discomfort [2]. The prevalence of FD is about $20-30 \%$ worldwide [3] while a study from India reports the prevalence of functional dyspepsia is $30.4 \%$ [4].

Abdominal pain interfering with normal sleep patterns or awakening the patient from sleep has traditionally been considered to be suggestive of organic diseases, although there is little evidence supporting this concept. Research into sleep and its associated health abnormalities has had a relatively recent surge and several studies have proved that sleep quality is an important and essential element of good health [5-6]. 
Some recent studies assessing self-reported quality of sleep suggest that patients with functional gastrointestinal disorders, in particular those with functional dyspepsia, are likely to suffer from poor sleep [7].

Common symptoms of a sleep disturbance include trouble falling asleep, early morning awakening, and daytime sleepiness as described by the PSQI and ISI scales. Sleep disturbance has been associated with a plethora of health problems, including decreased cognitive function, slowing of reflexes, cardiovascular disease, reduced work productivity, and impaired quality of life [8-9]. Various studies have demonstrated that irritable bowel syndrome (IBS) and gastroesophageal reflux disease (GERD) are associated with sleep disturbances [10-14]. Unlike GERD and IBS, the relationship between sleep disorders and functional dyspepsia (FD) is not still well characterized. We aim to provide some insights into this relationship through our study.

\section{METHODOLOGY}

The study design was cross-sectional, case-control, observational in nature and carried out in the gastrointestinal OPD of a public sector tertiary care hospital over a period of 2 months (August- September 2018). Patients of functional dyspepsia and their relatives attending the Gastro Intestinal Out Patient Department (GI OPD) were the subjects of the study. A sample size of 100 in the patient group and 100 in the control group was included in the study population. The control group comprised of persons who had accompanied the patients to the GI OPD.

\section{Inclusion criteria:}

- All participants must be above 18 years of age.

- All the patients and/or relatives willing to participate and giving informed consent for the study.

- Patients diagnosed with functional dyspepsia by 2 gastroenterologists after performing endoscopy to rule out any organic causes.

\section{Exclusion criteria}

- Patients with chronic debilitating diseases such as cancer, liver, renal and cardiac diseases.

- Pregnant or lactating females

- Patients or controls having a diagnosed case of any psychiatric illness

- Controls having any apparent GI symptoms

\section{Survey instruments}

- Semi-structured proforma for collecting socio- demographic details: Demographic details like name, age, sex, address, occupation, employment status, education levels, marital status and religion were noted.

- Bowel symptom questionnaire: A functional dyspepsia questionnaire based on a pre designed functional bowel symptoms questionnaire was used. 19 items on functional dyspepsia and 5 items on the pain index from this questionnaire were used in this study to assess phenomenological details [15].

- Pittsburgh sleep quality index (PSQI): Consisting of 19 items, the PSQI measures several different aspects of sleep, offering seven component scores and one composite score. The component scores incorporate subjective sleep quality, sleep latency (i.e., how long it takes to fall asleep), sleep duration, habitual sleep efficiency (i.e., the percentage of time in bed that one is asleep), sleep disturbances, use of sleeping medication and daytime dysfunction [16]. A 0-3 interval scale is used for each item. The global PSQI score is calculated by adding the seven component scores, providing a total score ranging from 0 to 21 , where lower scores indicate a healthier sleep quality. A score of less than 5 is considered normal. A score of 5 or above indicates impaired sleep quality [16-17]. 
- Insomnia severity index: This scale is designed to assess the nature, severity, and impact of insomnia and to monitor treatment response in adults. It consists of 7 items belonging to various categories. These categories include severity of sleep onset, sleep maintenance, early morning wakening problems, sleep dissatisfaction, interference of sleep difficulties with daytime functioning, noticeability of sleep problems by others and distress caused by the sleep difficulties. The scale is scored on a 5 point Likert scale $(0=$ no problem, $4=$ very severe problem $)$ and the scores are in the range $0-7=$ No clinically significant insomnia, $8-14=$ Subthreshold insomnia, $15-21=$ Clinical insomnia (moderate severity), 22-28 = Clinical insomnia (severe) [18-19].

Ethics committee approval was obtained from the institutional ethics committee. Informed consent was taken in the attached proforma and following data was collected. The demographic profile was collected in the semi-structured proforma. The phenomenology of FD including age of onset, duration, course of illness and details of other associated problems like nausea and vomiting were taken. 2 questionnaires were administered to assess the sleep quality of the patients. These included PSQI and ISI to assess sleep quality and severity of insomnia respectively. To overcome language barriers, the informed consent was printed in 3 languages common in the region of study. The subjects were verbally interviewed in their language of choice if they could not read the questionnaires due to illiteracy or language barrier. The same interviewer interviewed all the patients to eliminate bias.

\section{STATISTICAL ANALYSIS}

The data obtained was entered into MS Excel sheet. Data analysis was done with the help of SPSS Version 22. The tests used were the chi square test, Student ' $t$ ' test and correlation was analysed using Pearson's correlation where appropriate.

\section{RESULTS}

Table 1 - Sociodemographic variables in both the groups

\begin{tabular}{|c|c|c|c|}
\hline \multirow[t]{2}{*}{$\begin{array}{c}\text { Sociodemographic } \\
\text { Variable }\end{array}$} & $\begin{array}{l}\text { Patient group } \\
(\mathrm{N}=100)\end{array}$ & $\begin{array}{c}\text { Control group } \\
(\mathrm{N}=100)\end{array}$ & \multirow[t]{2}{*}{$\begin{array}{c}\text { Statistical } \\
\text { Analysis }\end{array}$} \\
\hline & \multicolumn{2}{|c|}{$\mathbf{N}$} & \\
\hline $\begin{array}{c}\text { Age } \\
<20 \text { years } \\
21-30 \text { years } \\
31-40 \text { years } \\
41-50 \text { years } \\
51-60 \text { years } \\
>61 \text { years }\end{array}$ & $\begin{array}{c}2 \\
23 \\
28 \\
18 \\
16 \\
13\end{array}$ & $\begin{array}{c}1 \\
21 \\
25 \\
31 \\
18 \\
4\end{array}$ & $\begin{array}{c}\mathrm{X}^{2}=8.925 \\
\mathrm{df}=5 \\
\mathrm{p}=0.112 \mathrm{NS}\end{array}$ \\
\hline $\begin{array}{l}\text { Gender } \\
\text { Male } \\
\text { Female }\end{array}$ & $\begin{array}{l}39 \\
61\end{array}$ & $\begin{array}{l}55 \\
45 \\
\end{array}$ & $\begin{array}{c}\mathrm{X}^{2}=5.138 ; \mathrm{df}=1 \\
\mathrm{p}=0.023^{*}\end{array}$ \\
\hline $\begin{array}{c}\text { Education } \\
\text { Illiterate } \\
\text { Primary School } \\
\text { Secondary School } \\
\text { Higher Secondary } \\
\text { Graduation } \\
\end{array}$ & $\begin{array}{c}14 \\
15 \\
47 \\
9 \\
15 \\
\end{array}$ & $\begin{array}{c}13 \\
12 \\
51 \\
8 \\
16 \\
\end{array}$ & $\begin{array}{c}\mathrm{X}^{2}=0.625 \\
\mathrm{df}=4 \\
\mathrm{p}=0.960 \mathrm{NS}\end{array}$ \\
\hline $\begin{array}{l}\text { Religion } \\
\text { Hindu } \\
\text { Muslim } \\
\end{array}$ & $\begin{array}{l}71 \\
29 \\
\end{array}$ & $\begin{array}{l}77 \\
23 \\
\end{array}$ & $\begin{array}{c}\mathrm{X}^{2}=0.936 ; \mathrm{df}=1 ; \\
\mathrm{p}=0.333 \mathrm{NS}\end{array}$ \\
\hline $\begin{array}{l}\text { Employment } \\
\text { Employed } \\
\text { Unemployed } \\
\text { Retired } \\
\end{array}$ & $\begin{array}{l}53 \\
37 \\
10 \\
\end{array}$ & $\begin{array}{c}43 \\
54 \\
3 \\
\end{array}$ & $\begin{array}{c}\mathrm{X}^{2}=7.987 ; \mathrm{df}=2 ; \\
\mathrm{p}=0.018^{*}\end{array}$ \\
\hline
\end{tabular}




\begin{tabular}{|c|c|c|c|}
\hline Marital Status & 77 & 86 & $\mathrm{X}^{2}=2.891$ \\
Married & 13 & 9 & $\mathrm{df}=2$ \\
Single & 10 & 5 & $\mathrm{p}=0.236 \mathrm{NS}$ \\
Widowed & & & \\
\hline Tobacco Use & 14 & 22 & $\mathrm{X}^{2}=2.168 ; \mathrm{df}=1 ;$ \\
Yes & 86 & 78 & $\mathrm{p}=0.141 \mathrm{NS}$ \\
No &
\end{tabular}

All statistics done using the Chi square test

Table 1 shows the socio-demographic data in both the groups. Both the groups were well matched in all respects. Significantly greater people in the control group were unemployed and male. In all other respects no differences were observed in the groups.

Table 2 - Characteristics of Functional Dyspepsia in the patient group $(\mathrm{N}=100)$

\begin{tabular}{|c|c|c|c|}
\hline \multirow[t]{2}{*}{ No. } & \multirow[t]{2}{*}{ Questions } & \multicolumn{2}{|c|}{$\mathbf{N}$} \\
\hline & & Yes & No \\
\hline 1. & Have you had this same ache or pain more than 6 times in the past year & 96 & 4 \\
\hline 2. & $\begin{array}{l}\text { How bad is the pain usually when it occurs - } \\
\text { No pain } \\
\text { Mild: can be ignored if you don't think about it } \\
\text { Moderate: cannot be ignored, but does not affect your life-style } \\
\text { Severe: affects your life-style } \\
\text { Very Severe: markedly affects your life-style }\end{array}$ & $\begin{array}{c}1 \\
18 \\
39 \\
28 \\
14\end{array}$ & $\begin{array}{l}- \\
- \\
- \\
- \\
-\end{array}$ \\
\hline 3. & $\begin{array}{l}\text { Does this pain come and go periodically } \\
\text { Periodically here means periods of at least a month with no pain, with periods in } \\
\text { between of weeks to months when there is pain. }\end{array}$ & 57 & 43 \\
\hline 4. & Does this ache or pain often occur before meals or when hungry & 55 & 45 \\
\hline 5. & $\begin{array}{l}\text { Does this ache or pain often occur immediately after (less than } 30 \text { mins) } \\
\text { meals }\end{array}$ & 41 & 59 \\
\hline 6. & Does this ache or pain often occur 30 minutes to 2 hours after meals & 56 & 44 \\
\hline 7. & $\begin{array}{l}\text { Is this pain often made better (relieved) by burping (bringing up air through } \\
\text { the mouth) }\end{array}$ & 61 & 39 \\
\hline 8. & Is this pain often made better by eating & 27 & 73 \\
\hline 9. & Does this pain often travel anywhere outside the belly & 36 & 64 \\
\hline 10. & Does your usual ache or pain ever wake you from sleep a & 71 & 29 \\
\hline 11. & Is this pain often made worse by food or milk & 59 & 41 \\
\hline 12. & $\begin{array}{l}\text { When in your life did this ache or pain first begin as close as you can recall } \\
7 \text { months to } 1 \text { year } \\
\text { In the last } 6 \text { months } \\
>1-2 \text { years } \\
>2-5 \text { years } \\
>5-10 \text { years } \\
>10 \text { years }\end{array}$ & $\begin{array}{l}15 \\
11 \\
21 \\
24 \\
21 \\
8\end{array}$ & $\begin{array}{l}- \\
- \\
- \\
- \\
- \\
-\end{array}$ \\
\hline 13. & Is this pain often made better by taking antacids & 57 & 22 \\
\hline 14. & $\begin{array}{l}\text { Is this pain often made worse by drinking alcohol } \\
\text { Do not drink alcohol }-82\end{array}$ & 11 & 7 \\
\hline 15. & Have you lost weight in the last year without deliberately dieting & 28 & 72 \\
\hline
\end{tabular}

Almost all patients suffering from FD had pain inthe belly more than 6 times in the past year whereas none of the controls had this complaint. The pain is usually moderate to severe in patients, occurs either before or half to two hours after meals and is made better by burping. Many patients sleep is disturbed due to the pain and that the pain is not relieved by eating, made worse by food or milk and does not travel outside the belly in majority. The pain began more than 2 years to 5 years ago, occurs daily and causes nausea about once in a month in most. It is relieved by antacids. There was decreased appetite in half of the patients while most of them report no weight change. 
Table 3 - Scores on the PSQI and ISI scales

\begin{tabular}{|c|c|c|c|}
\hline Variables & Patient Group (N=100) & Control Group (N=100) & Statistical Analysis \\
\hline PSQI final scores & $10.43 \pm 4.81$ & $1.93 \pm 2.41$ & $\mathrm{p}=0.0001^{* \mathrm{a}}$ \\
\hline ISI final scores & $15.32 \pm 7.62$ & $3.94 \pm 3.68$ & $\mathrm{p}=0.0001^{* \mathrm{a}}$ \\
\hline PSQI Scores & & & \\
$<5$ & 17 & 94 & $\mathrm{X}^{2}=120.03 ; \mathrm{df}=1 ;$ \\
$\geq 5$ & 83 & 6 & $\mathrm{p}=0.00001^{* \mathrm{~b}}$ \\
\hline ISI scores & 17 & 93 & $\mathrm{X}^{2}=117.33 ; \mathrm{df}=3 ;$ \\
$0-7$ & 25 & 4 & $\mathrm{p}=0.00001^{* \mathrm{~b}}$ \\
$8-14$ & 33 & 2 & \\
$15-21$ & 25 & 1 & \\
$22-28$ & & & \\
\hline
\end{tabular}

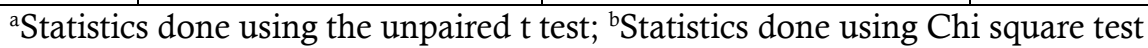

As seen in the table above, patients had significantly greater scores on both the sleep parameter scales as compared to controls. There is a high degree of correlation between the scores of PSQI and ISI. This emphasizes the results that sleep disturbances are more common in FD (Figure 1).

Figure 1 - Scatter plot between scores on PSQI and ISI

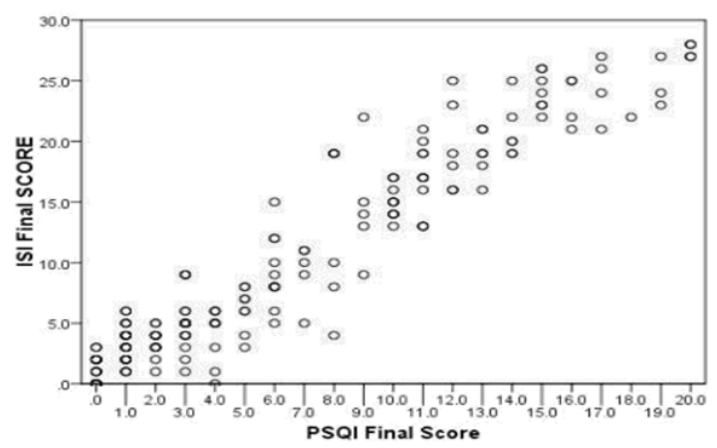

\section{DISCUSSION}

In our study, most of the patients belonged to the age group of 30-40 years but not very significant. Previous studies also report similar results. In a Norwegian total population survey in 1988, they reported the lifetime prevalence of non-ulcer dyspepsia to be $23 \%$ among males and $18 \%$ among females. Our findings also reveal higher prevalence of FD in males. However, other studies report no significant findings on the basis of gender [20]. In two studies published by Jones and Lydeard in 1989 and 1990, the prevalence of FD was $38 \%$ and $41 \%$ in their 6-month study period and there was no difference between males and females [21-22].

Dyspepsia is a common, long term, symptom shifting, and expensive disorder. It has been reported that about $86 \%$ of individuals with frequent symptoms had the same symptoms even after 12-20 months [23]. This is also enunciated in our study, in which most of the patients have been suffering from dyspeptic symptoms from the past 2-5 years. According to a study, no significant differences were found between FD patients and controls with regard to tobacco and use [24]. Similar findings were reported in our study also.

\section{Sleep Questionnaires}

According to a study significantly higher PSQI scores were found for patients with FD compared with healthy controls [25]. Total PSQI scores were higher in FD patients with moderate symptoms and in patients with severe symptoms when compared with those with mild symptoms and to healthy controls. ISI scores 
were higher in FD patients with moderate and severe symptoms compared with those with mild symptoms and healthy controls. Similar significant findings were obtained in our study.

\section{CONCLUSIONS}

This was a cross-sectional, case- control and observational study designed to find the sleep disturbances in patients having diagnosed Functional Dyspepsia in a sample of 100 patients compared with 100 persons in control group. Significant relationship between sleep disturbances and FD was established in the study. Further larger studies in diverse clinical populations with FD are needed to give impetus to these findings.

\section{REFERENCES}

1. Tack J, Bisschops RA, Sarnelli G. Pathophysiology and treatment of functional dyspepsia. Gastroenterology 2004;127(4):1239-55.

2. Lacy BE, Talley NJ, Locke III GR, Bouras EP, DiBaise JK, El- Serag HB, Abraham BP, Howden CW, Moayyedi P, Prather C. current treatment options and management of functional dyspepsia. Aliment Pharmacol Therapeut 2012;36(1):3-15.

3. Ghoshal UC, Singh R, Chang FY, Hou X, Wong BC, Kachintorn U. Epidemiology of uninvestigated and functional dyspepsia in Asia: facts and fiction. J Neurogastroenterol Motility 2011;17(3):235-44.

4. Mahadeva S, Goh KL. Epidemiology of functional dyspepsia: a global perspective. World J Gastroenterol 2006;12(17):2661-6.

5. Tack J, Lee KJ. Pathophysiology and treatment of functional dyspepsia. J Clin Gastroenterol 2005;39(5):S2116.

6. Camilleri M, Stanghellini V. Current management strategies and emerging treatments for functional dyspepsia. Nat Rev Gastroenterol Hepatol 2013;10(3):187-94.

7. Lacy BE, Everhart K, Crowell MD. Functional dyspepsia is associated with sleep disorders. Clin Gastroenterol Hepatol 2011;9(5):410-4.

8. Yamawaki H, Futagami S, Shimpuku M, Sato H, Wakabayashi T, Maruki Y, Kodaka Y, Nagoya H, Shindo T, Kawagoe T, Sakamoto C. Impact of sleep disorders, quality of life and gastric emptying in distinct subtypes of functional dyspepsia in Japan. J Neurogastroenterol Motil 2014;20(1):104-9.

9. Futagami S, Yamawaki H, Izumi N, Shimpuku M, Kodaka Y, Wakabayashi T, Nagoya H, Shindo T, Kawagoe T, Gudis K, Itoh T. Impact of sleep disorders in J apanese patients with functional dyspepsia (FD): Nizatidine improves clinical symptoms, gastric emptying and sleep disorders in FD patients. J Gastroenterol Hepatol 2013;28(8):1314-20.

10. El- Serag HB, Talley NJ. Health- related quality of life in functional dyspepsia. Aliment Pharmacol Therapeut 2003;18(4):387-93.

11. Futagami S, Shimpuku M, Yamawaki H, Izumi N, Kodaka Y, Nagoya H, Wakabayashi T, Shindo T, Kawagoe T, Sakamoto C. Sleep disorders in functional dyspepsia and future therapy. J Nippon Med School 2013;80(2):104-9.

12. Kim SY, Choung RS, Lee SK, Choe JW, Jung SW, Hyun JJ, Koo JS, Lee SW, Shin C. Self-reported sleep impairment in functional dyspepsia and irritable bowel syndrome. J Neurogastroenterol Motil 2018;24(2):2808.

13. Li Y, Gong Y, Li Y, He D, Wu Y, Wang H, Cong X, Wei M, Lin L. Sleep disturbance and psychological distress are associated with functional dyspepsia based on Rome III criteria. BMC Psychiatry 2018;18(1):133.

14. Matsuzaki J, Suzuki H, Togawa K, Yamane T, Mori H, Komori T, Masaoka T, Kanai T. Burden of impaired sleep quality on work productivity in functional dyspepsia. United Eur Gastroenterol J 2018;6(3):398-406.

15. Talley NJ, Newman P, Boyce PM, Paterson KJ, Owen BK. Initial validation of a bowel symptom questionnaire* and measurement of chronic gastrointestinal symptoms in Australians. Austr NZ J Med 1995;25(4):302-8.

16. Buysse DJ, Reynolds CF, Monk TH, Berman SR, Kupfer DJ. The Pittsburgh Sleep Quality Index: a new instrument for psychiatric practice and research. Psychiatr Res 1989;28(2):193-213.

17. Carpenter JS, Andrykowski MA. Psychometric evaluation of the Pittsburgh sleep quality index. J Psychosom Res 1998;45(1):5-13.

18. Bastien $\mathrm{CH}$, Vallières A, Morin CM. Validation of the Insomnia Severity Index as an outcome measure for insomnia research. Sleep Med 2001;2(4):297-307.

19. Morin CM, Belleville G, Bélanger L, Ivers H. The Insomnia Severity Index: psychometric indicators to detect insomnia cases and evaluate treatment response. Sleep 2011;34(5):601-8.

20. Aziz I, Palsson OS, Törnblom H, Sperber AD, Whitehead WE, Simrén M. Epidemiology, clinical characteristics, and associations for symptom-based Rome IV functional dyspepsia in adults in the USA, Canada, and the UK: a cross-sectional population-based study. Lancet Gastroenterol Hepatol 2018;3(4):25262. 
21. Knill-Jones RP. Geographical differences in the prevalence of dyspepsia. Scand J Gastroenterol 1991;26(sup182):17-24.

22. Grainger SL, Klass HJ, Rake MO, Williams JG. Prevalence of dyspepsia: the epidemiology of overlapping symptoms. Postgrad Med J 1994;70(821):154-61.

23. Koh SJ, Kim M, Da Yeon Oh BG, Lee KL, Kim JW. Psychosocial stress in nurses with shift work schedule is associated with functional gastrointestinal disorders. J Neurogastroenterol Motil 2014;20(4):516-22.

24. Richter JE. Stress and psychologic and environmental factors in functional dyspepsia. Scand J Gastroenterol 1991;26(sup182):40-6.

$* * * * * * * * * * * * * * * * * * * * * * * * * * * * * * * * * * * *$

Acknowledgements - Nil

Conflict of Interest - Nil

Funding - Nil 